International Journal of Engineering \& Technology, $7(4.5)(2018) 662-664$
International Journal of Engineering \& Technology
SPC
Website $: \frac{w w w . s c i e n c e p u b c o . c o m / i n d e x . p h p / I J E T}{2}$
Research paper

\title{
Active \& reactive powers control of DFIG placed with wind energy system by using hybrid controller
}

\author{
M. Vasavi Uma Maheswari ${ }^{1}{ }^{*}$, Dr. P. V. Ramana Rao ${ }^{2}$ \\ ${ }^{1}$ Asset Professor EEE Department College of Engineering \& Technology Acharya Nagarjuna University Guntur, Andhra Pradesh \\ ${ }^{2}$ Professor EEE Department College of Engineering \& Technology Acharya Nagarjuna University Guntur, Andhra Pradesh \\ *Corresponding author E-mail: vasavimajety.eee@gmail.com
}

\begin{abstract}
Here paper presents around the Active power along with Reactive power clout of a grid allied doubly fed Induction Generator (DFIG) with wind energy system (WES) employing PI \& ANFIS controller. DFIG is formed adapting a d-q revolving allusion cage circuit with stator flux oriented, field oriented clout approach. By using a coterminous converter of Variable speed constant Frequency (VSCF) along with active the reactive power and DC tie voltage are controlled at sub and super synchronous speeds. An ANFIS has been coupled by a conventional PI controller in order to enhance the power controlling capability at steady state and voltage dip conditions
\end{abstract}

Keywords: DFIG; WECS; Variable Speed Constant Frequency (VSCF); ANFIS Controller.

\section{Introduction}

In forthcoming most of power generating is awakening towards renewable energy sources in which wind energy power generation is the major inviting source compared with other generators [1]. DFIG is the mostly used generator in wind power generation because of the quality of power, reducing proponent capacity and grid link utility. Controlling and enhancing the potent characteristics of fickle speed uninterrupted frequency control of DFIG are very crucial in wind energy research.

Controlling of DFIG is mainly concentrated at back to back converters connected in the rotor circuit [2]. The proponent coupled to the grid acts as grid incidental coterminous (GIC) and it mainly furnishes a reliable DC tie voltage. This DC tie voltage acts as a source for the other coterminous which is coupled to the rotor known as rotor incidental coterminous (RIC).

The special working of GIC is to stabilize the DC tie voltage and in addition to this it also eliminates the reactive power puls under unbalanced situations. The RIC provides the required magnetization current wave in rotor windings and controls both powers at the stator terminals. Compared to the fixed speed system, DFIG energy capture enhances by $60 \%$ approximately. GIC and RIC are interlinked to each other such that the GIC set points would be derived or extracted from the RIC set points and the turbine generator working condition. Real time power control are done based on controlling the GIC and RIC using conventional PI controllers [3]. In general direction control and actual power controllers are used to regulate power generated by DFIG.

This paper proposes control scheme for DFIG which adapts fieldoriented control theory to control RIC and GIC by hysteresis control DC link voltage as a constant and adds an Adaptive Neuro Fuzzy Inference System in addition to conventional PI controller for controlling the GIC and RIC. The current control strategies PI are based on linearized circuit. Tuning of a PI controller needs much effort and it will not give expected results under parameter variations condition, load interruption and for energy changes in wind. In DFIG to controlling the rotor currents, powers are also controlled independently with the help of RIC. However power exchange with the rotor converter and additional reactive support can be attained from GIC. ANFIS is to makes use of Hybrid learning rules to optimize the fuzzy system parameters of first order sugeno systems. It is seen from the architecture of ANFIS that it has 5 layers, first layer is to fuzzifaction of the input changed to generate the membership. $2^{\text {nd }}$ layer generates the strength of the membership grades $3^{\text {rd }}$ layer normalizes the firing strengths $4^{\text {th }}$ layer calculates the consequent parameters as outputs $5^{\text {th }}$ layer sums up all the $4^{\text {th }}$ layer outputs which is the total output of the ANFIS controller System [4]. This is shown in fig 1.1

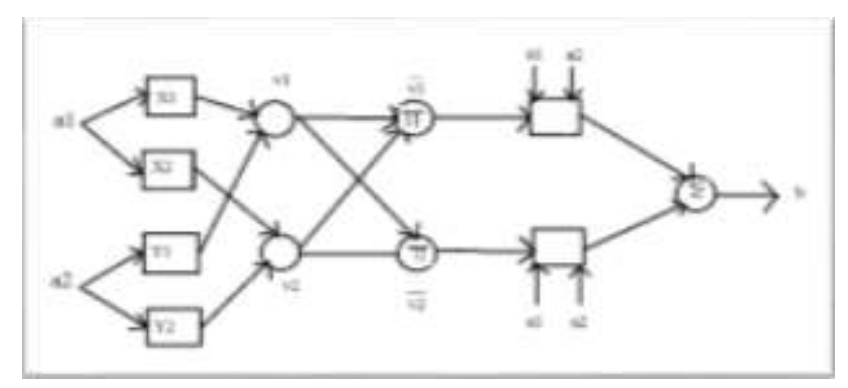

Fig. 1.1: ANFIS Architecture.

The expressions for the above architecture are given below

$$
\mathrm{Li}^{1}=\mathrm{f}(\mathrm{x})
$$

' $\mathrm{f}$ ' is the membership function of Neuro Fuzzy Inference System.

$\mathrm{L}_{\mathrm{i}}^{2}=\mathrm{v}_{\mathrm{i}}=\pi_{\mathrm{j}=1} \mathrm{f}(\mathrm{x})$

Eq. 2 is the $2^{\text {nd }}$ layer generates the firing strength. 
$\mathrm{L}_{\mathrm{i}}{ }^{3}=\overline{\mathrm{v}}_{\mathrm{i}}=\left(\mathrm{v}_{\mathrm{i}} /\left[\mathrm{v}_{1}+\mathrm{v}_{2}\right]\right)$

Eq. 3 is the $3^{\text {rd }}$ layer normalizes the firing strength.

$\mathrm{L}_{\mathrm{i}}{ }^{4}=\mathrm{b}_{\mathrm{i}}=\overline{\mathrm{V}}_{\mathrm{I}} * \mathrm{~g}_{\mathrm{i}}=\overline{\mathrm{V}}_{\mathrm{I}}\left(\mathrm{p}_{\mathrm{i}} * \mathrm{a}+\mathrm{q}_{\mathrm{i}} * \mathrm{~b}+\mathrm{r}_{\mathrm{i}}\right)$

Is the fourth layer calculates the consequent outputs.

$\mathrm{B}=\mathrm{L}_{\mathrm{i}}^{5}=\sum \mathrm{I} \mathrm{b}_{\mathrm{i}}=\sum_{\mathrm{I}} \overline{\mathrm{V}}_{\mathrm{I}} * \mathrm{~g}_{\mathrm{i}}=\sum_{\mathrm{i}} \overline{\mathrm{V}}_{\mathrm{I}}\left(\mathrm{p}_{\mathrm{i}} * \mathrm{a}+\mathrm{q}_{\mathrm{i}} * \mathrm{~b}+\mathrm{r}_{\mathrm{i}}\right)$

Is the sum of the outputs.

The procedure of ANFIS network has following 2 steps.

1) All the inputs are are estimated by iterative LMSP.

2) The patterns are propagated again and applied to change parameters. This procedure is iterated until $\mathrm{B}=\mathrm{A} * \mathrm{~V}$ Satisfies

Where A ---- vector of predictors.

$\mathrm{V}$---- Is the Vector

Tune local parameters of an ANFIS network and The network gives error $e_{b}$ is the output. The parameters are updated until the error is minimized.

\section{Identification and control of DFIG using ANFIS controller}

The ANFIS input is derived from $b(t)$ of the DFIG output and ANFIS output. The estimation of the signal to control of DFIG converter pulses to both RSC and GSC. This ensures stabilizing the voltage at DC link, supporting power from GSC and controlling powers from RSC. ANFIS network used contains total

No. of nodes $=44$

No. of linear parameters $=20$

No. of nonlinear parameters $=30$

No. of training data parameters' $=10$

No. of Fuzzy rules $=10$

The inputs to the ANFIS control are obtained with including error and then the respective voltages are calculated from which the pulses can be calculated for both the RSC and GSC are show in fig 2.1 and 2.2

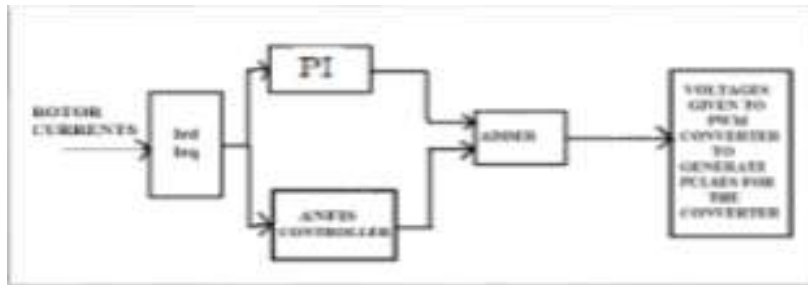

Fig. 2.1: Shows of Hybrid Control Including PI and ANFIS for RIC.

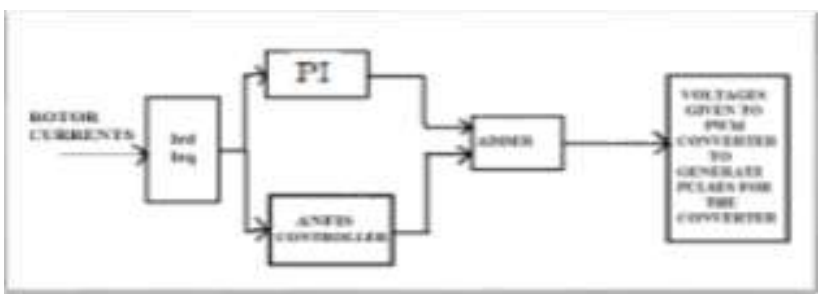

Fig. 2.2: Shows Hybrid Control Including PI and ANFIS for GIC.

From the figure it is observed that the controller is added in the current loop output of which is used to calculate the reference voltages for generating the pulses for both RIC and GIC.

\section{Simulink model of hybrid control adapted in both RIC and GIC}

The model is implemented in MATLAB its simulation model adopted with Hybrid controller in both Grid Side Converter and Rotor Side Converter are given below in fig 3.1 and fig 3.2. The enhancement of the performance with Hybrid controller is also evaluated. The Matlab model is designed with $1.5 \mathrm{MW}$ wind farm subsist of $1.5 \mathrm{MW}$ wind turbine connected to $25 \mathrm{kV}$ distribution system dump $120 \mathrm{kV}$ grid through a $30 \mathrm{~km} 25 \mathrm{kV}$ feeder.

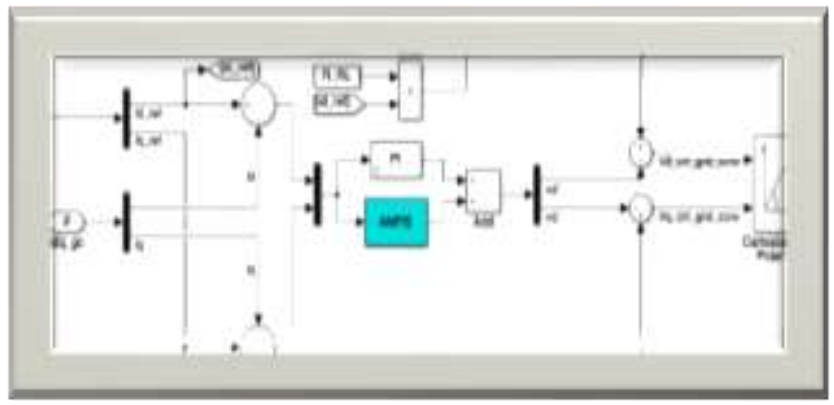

Fig. 3.1: Simulink Diagram of Grid Side Controller Including Conventional PI \& ANFIS Controllers.

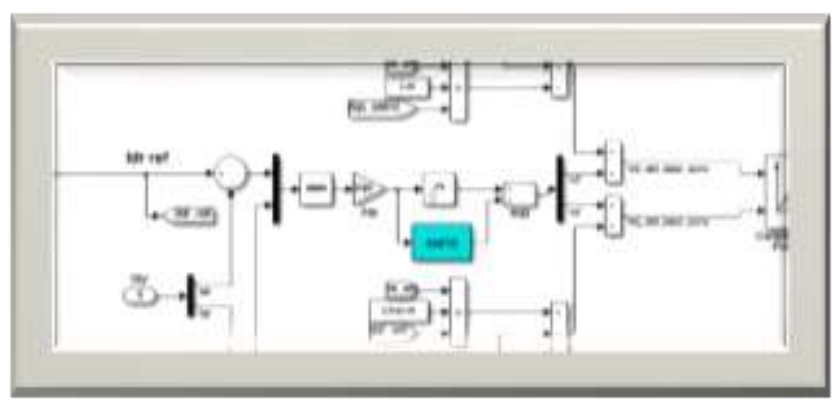

Fig. 3.2: Simulink Diagram of Rotor Side Controller Including Conventional PI\& ANFIS Controller.

\section{Results}

The following simulation results given in fig 4.1, 4.2 4.3, 4.4 correspond to powers of the DFIG at source steady state conditions. Similarly fig 4.5,4.6,4.7,4.8 are the powers of DFIG with voltage dip 20 percent from time interval of 0.2 milli sec to 0.3 milli sec. Fig 4.1 and fig 4.3 are active and reactive powers adapting Hybrid controller and fig 4.2 and fig 4.4 are active and reactive powers adapting Conventional PI controller. Fig 4.5 and 4.7 are active and reactive powers adapting Hybrid controller with a voltage dip and fig. 4.6 and 4.8 are powers adapting with Conventional PI controller.

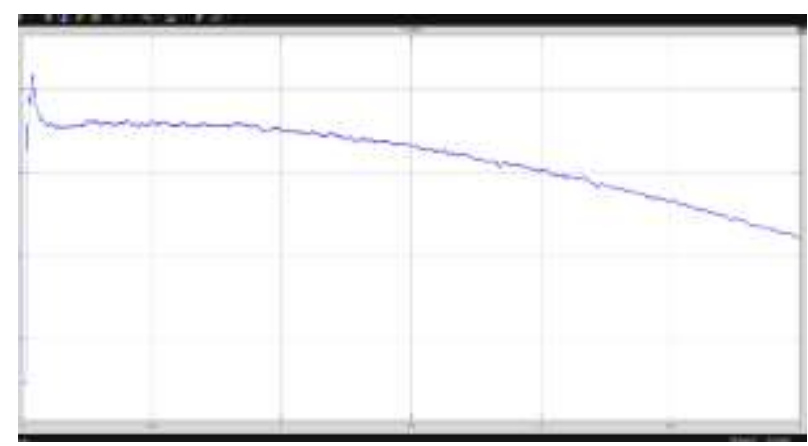

Fig. 4.1: 


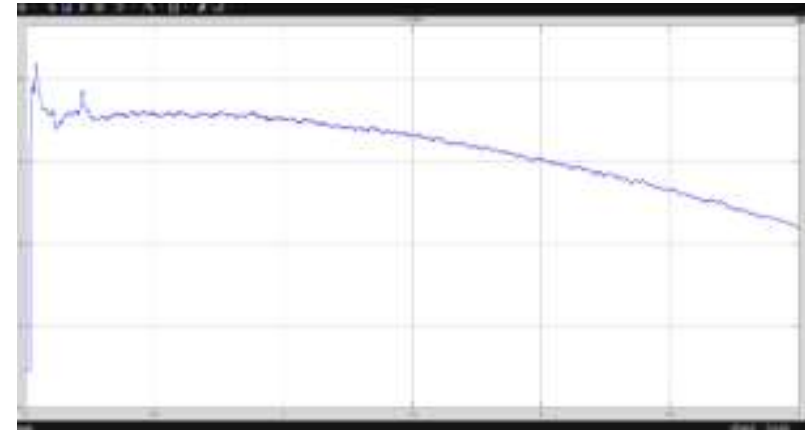

Fig.4.2:

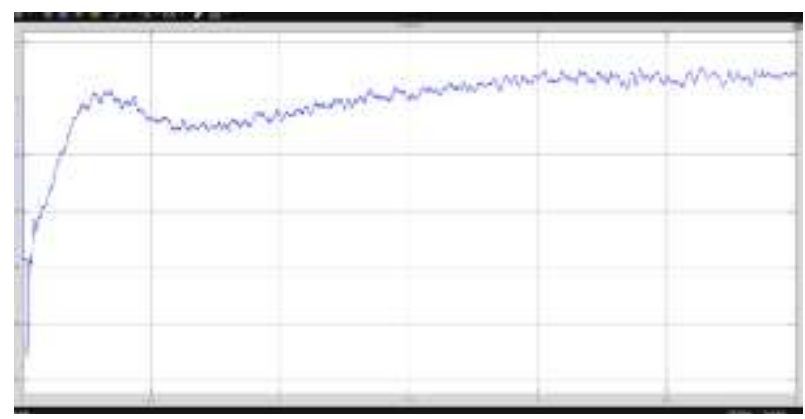

Fig. 4.3:

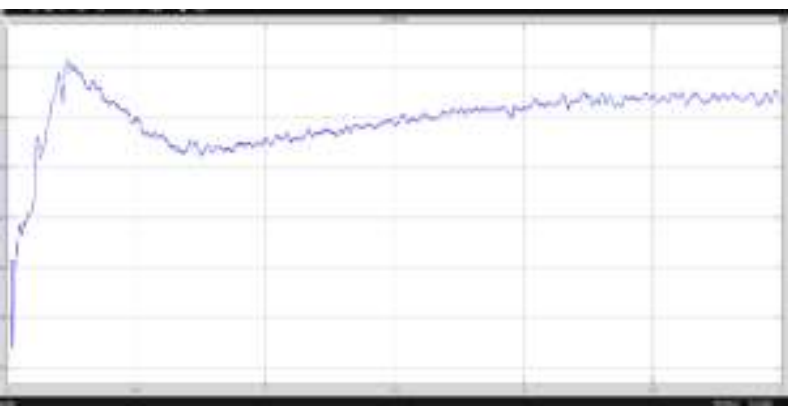

Fig. 4.4:

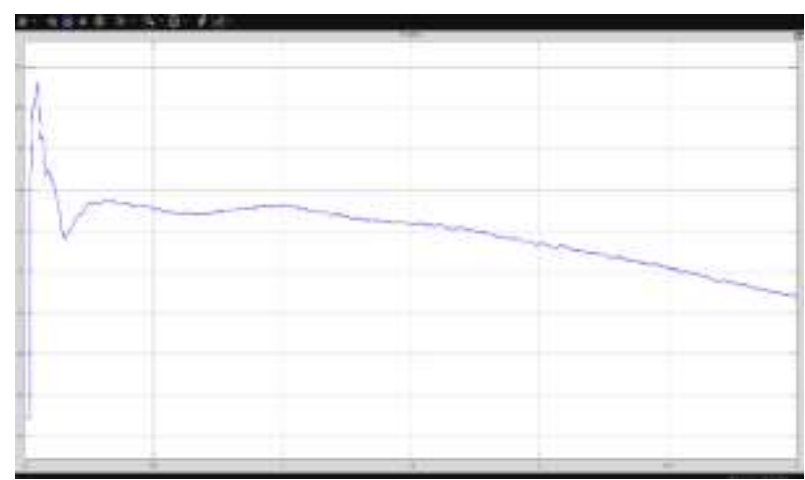

Fig. 4.5:

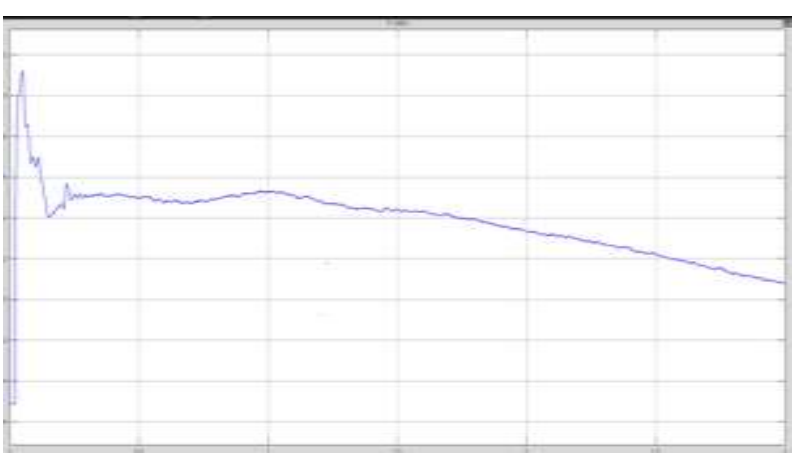

Fig. 4.6:

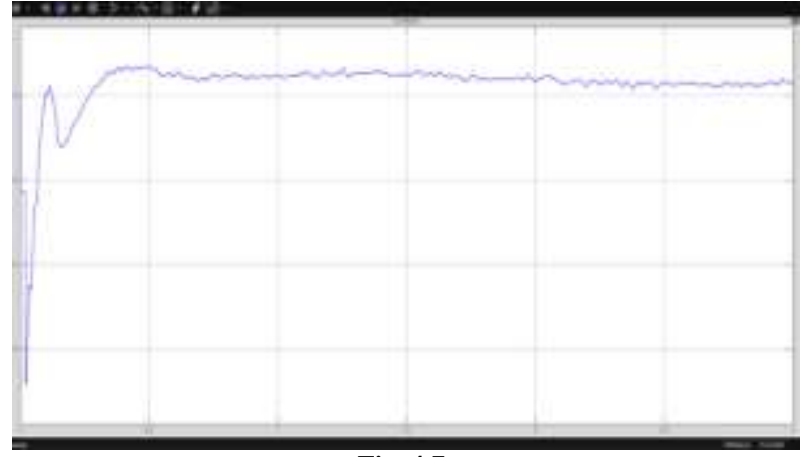

Fig. 4.7:

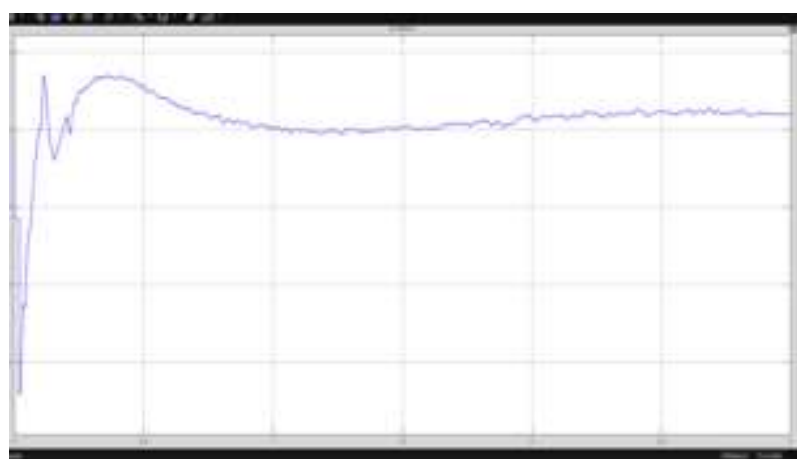

Fig. 4.8:

\section{Conclusion}

In aforementioned work a Hybrid Controller adopted with a Conventional PI and ANFIS is planned for Wind Energy Systems. The achievement of Hybrid controller is upgraded with a Conventional PI controller.

\section{References}

[1] Juber Ahmed, Zainal Salam, A Maximum Power Point Tracking (MPPT) for PV system using Cuckoo Search with partial shading capability Applied Energy 119(2014) 118-130.

[2] Maximum Energy Output of a DFIGWind Turbine Using an Improved MPPT-Curve Method.

[3] Dinh-Chung Phan 1; 2 and Shigeru Yamamoto. Energies 2015, 8, 11718-11736; doi: 10.3390/en81011718, ISSN 1996-1073.

[4] Real-Time Control of Active and Reactive Power for Doubly Fed Induction Generator (DFIG)-Based Wind Energy Conversion System Aman Abdulla Tanvir 1,*, Adel Merabet 1 and Rachid Beguenane, ISSN 1996-1073, Energies 2015, 8, 10389-10408; doi:10.3390/en80910389.

[5] Coordinated control of rotor and grid sides converters in DFIG based wind turbines for providing optimal reactive power support and voltage regulation Mohsen Rahimi Sustainable Energy Technologies and Assessments 20 (2017) 47-57. 